\title{
Pengaruh E-servqual Terhadap E-Loyality Pada Pelanggan Traveloka
}

\author{
Ira Nuriya Santi*, Muzakir, Wahyuningsih \\ Fakultas Ekonomi dan Bisnis Universitas Tadulako \\ Tondo, Palu, Sulawesi Tengah 94148 \\ E-mail: ira_nuria@yahoo.com
}

\begin{abstract}
Abstrak
Penelitian ini bertujuan untuk mengetahui pengaruh e-servqual yang sudah dimodifikasi dengan tambahan 2 variabel terhadap e-loyality, menggunakan pendekatan riset kuantitatif, populasinya adalah pengguna jasa layanan Traveloka di Indonesia dan jumlah sampel 262 responden, analisis regresi liner berganda digunakan sebagai metode analisis data, hasil kajian mengungkapkan e-servqual berpengaruh terhadap e-loyality, dan implikasi penelitian adalah hendaknya Traveloka memberikan perhatian lebih terhadap segmen yang ditemukan dalam penelitian ini, sehingga dapat membuat strategi pemasaran yang tepat agar tidak salah sasaran.
\end{abstract}

Kata Kunci: e-servqual, e-loyality, strategi pemasaran, e-commerce dan strategi pemasaran.

\section{Pendahuluan}

Kemajuan teknologi di bidang informasi dan telekomunikasi serta komunikasi menimbulkan terjadinya perubahan budaya. E-service quality (e-servqual) merupakan salah satu dimensi dalam ilmu pemasaran yang paling dramatis terpengaruh oleh perkembangan teknologi informasi dan komunikasi (Blut, 2016; Chu, Lee, \& Chao, 2012; Li, Liu, \& Suomi, 2009). Kini semua informasi melalui internet dapat dicapai dengan mudah dan cepat. Pengguna internet dapat meningkatkan pendapatannya dengan memanfaatkan internet sebagai sarana promosi yang tepat untuk bisnisnya serta sebagai dasar untuk pengambilan keputusan.

Fakta perubahan saat ini penuh dengan ketidakpastian. Banyaknya disrupsi (gangguan) yang terjadi, menciptakan peluang sekaligus ancaman bagi perusahaan, karena seluruh dunia telah mengalami perubahan dari berbagai sisi yang dipengaruhi oleh revolusi teknologi, generasi baru dan kecepatan kebutuhan yang luar biasa. Fakta ini menjadi tugas penting bagi perusahaan yang ingin menciptakan produk dan jasa untuk memenuhi keinginan pelanggan dan menjalin hubungan yang dekat melalui penciptaaan kualitas pelayanan secara online. Melihat kondisi ini, dibutuhkan rekonstruksi kualitas layanan dari literatur dan penelitian yang sudah ada sebelumnya menjadi kualitas layanan yang baru khususnya di dunia e-commerce disebut dengan kualitas layanan berbasis internet (Blut, 2016; Chu et al., 2012; Jonathan, 2013; Li et al., 2009; Parasuraman, Zeithaml, \& Malhotra, 2005; Sahadev \& Purani, 2008)

Aktivitas ekonomi dan bisnis membentuk gaya hidup online pada masyarakat, seperti kegiatan berbelanja yang dulunya hanya dikenal melalui toko fisik, sekarang sudah dapat dilakukan secara online (Choo, Park, \& Petrick, 2011; Pool, Dehghan, Jamkhaneh, Jaberi, \& Sharifkhani, 2018; Rowley, 2006; Tsang, Lai, \& Law, 2010). Proses jual-beli yang dulunya mengharuskan konsumen untuk bertatap muka, sekarang hanya menjadi sebatas menekan layar (klik) di gadget yang terkoneksi dengan internet. Transaksi bisnis secara online melalui media internet dan perangkat-perangkat yang terintegrasi dengan internet tersebut termasuk dalam $e$ commerce (Laudon \& Traver, 2017).

E-Commerce menjadi tren di lingkungan masyarakat sebagai salah satu upaya untuk memenuhi kebutuhan manusia dengan cara yang lebih efektif dan efisien. Pertumbuhan e-commerce di Indonesia bukan tanpa hambatan. Hal yang dapat menghambat laju perkembangan e-Commerce di Indonesia salah satunya adalah masyarakat yang takut untuk mulai melakukan transaksi online (Gaertner \& Smith, 2001; Sukma, 2019). Selain ketakutan dalam berbelanja online, terdapat masalah lainnya yaitu keamanan dalam berbelanja. Selain itu, sebagian besar pengguna internet masih ingin bertransaksi secara tradisional. Hal itu dilakukan untuk memastikan barang yang dibeli sesuai dengan keinginan.

Dunia start-up sekarang memiliki empat unicorn, salah satunya layanan perjalanan online atau saat ini dikenal dengan Online Travel Agencies (OTA) yaitu Traveloka. Aktivitas Online Travel Agencies (OTA), sebagai ecommerce. Adanya pergeseran gaya hidup Indonesia saat ini, masyarakat kelas menengah ke atas pengeluaran konsumsinya lebih fokus untuk pengalaman (experiences) daripada untuk barang-barang konsumsi fisik, memungkinkan bisnis travel online tumbuh subur. Tabel 1 berikut ini memperlihatkan peringkat situs start-up online travel di Indonesia:

Tabel 1. Peringkat Situs Start-up online Travel di Indonesia

\begin{tabular}{ccccc}
\hline No. & Startup & Score & $\begin{array}{c}\text { Rank } \\
\text { WordWide }\end{array}$ & $\begin{array}{c}\text { Rank } \\
\text { Indonesia }\end{array}$ \\
\hline 1 & Traveloka & 86.562 & 39 & 3 \\
2 & Pegipegi & 80.602 & 367 & 19 \\
3 & Nusatrip & 72.348 & 1.183 & 60 \\
4 & misteraladin & 68.983 & 1.549 & 80 \\
5 & Tiket.com & 58.964 & 2.491 & 120 \\
6 & Klikhotel & 57.640 & 2.606 & 126 \\
7 & Travelio & 57.403 & 2.631 & 130 \\
8 & Utiket & 57.364 & 2.636 & 131 \\
9 & arenatiket & 43861 & 3.992 & 200 \\
\hline
\end{tabular}

Sumber: www.sturtupranking.com. 2018

Kepuasan pelanggan yang berulang pada pembelian atau penggunaan produk atau layanan dari situs website ecommerce tertentu dapat memunculkan kesetiaan (loyalitas) pengguna layanan elektronik dimana hal itu dapat tercipta karena konstruksi yang dibangun perusahaan pada dimensi kualitas layanan elektronik (e-service quality).

* Corresponding author 
Li ( $\mathrm{Li}$ et al., 2009) dalam penelitiannya secara khusus mengukur penerapan dimensi e-service quality pada layanan perjalanan online di Cina. Hasil penelitiannya menunjukkan bahwa kepercayaan (trust) dari perspektif pelanggan dan kemudahan penggunaan (ease of use) dari perspektif perusahaan online adalah aspek yang paling kritis dan penting dalam persepsi pelanggan tentang kualitas layanan perjalanan online, sementara keandalan (reliability), ketersediaan sistem (system availability) dan daya tanggap (responsiveness) juga memiliki pengaruh pada persepsi pelanggan tentang kualitas layanan perjalanan online.

Konstruk atau dimensi e-service quality didefinisikan secara luas untuk mencakup semua fase interaksi pelanggan dengan layanan jasa dan penjualan online. Wolfinbarger dan Gilly (Wolfinbarger \& Gilly, 2003) mendefinisikan kualitas layanan elektronik (E-service quality) sebagai tindakan pengguna jasa layanan online dari mulai masuk website hingga akhir transaksi, prosesnya dimulai dari mencari informasi, pengisian data privasi, navigasi situs website, proses pemesanan produk, layanan interaksi dengan pelanggan, pengiriman barang, kebijakan barang retur, dan kesesuaian produk yang dipesan konsumen. Jadi, proses eservice quality mencakup banyak atribut jasa yang ada di toko online, seperti daya tarik barang yang dijual, kenyamanan proses pemesanan, dan kebijakan pengembalian barang yang tidak sesuai dengan kualitas yang diharapkan.

Penelitian (Blut, 2016) mengenai e-service quality menemukan bahwa konstruk/dimensi e-service quality sesuai dengan struktur model faktor yang menghubungkan persepsi kualitas layanan online ke dimensi yang berbeda dan dapat ditindaklanjuti dalam berbagai riset layanan online, menemukan empat dimensi membentuk pengukuran eservice quality sebagai penyempurnaan dari dimensi yang dibangun oleh berbagai teori sebelumnya yaitu dimensi (1) desain situs website (website design), (2) pemenuhan (fulfillment), (3) layanan pelanggan (customer service), dan (4) keamanan/privasi (security/privacy).

Efisiensi sebagai pertimbangan utama dalam menilai kualitas jasa layanan online adalah sebuah keniscayaan. Efisiensi sebagai kemudahan dan kecepatan mengakses dalam menggunakan situs. Suatu perusahaan yang efisien adalah perusahaan yang dalam produksinya menghasilkan barang atau jasa dengan cepat, lancar dan dengan biaya yang minimum termasuk layanan online service. Dalam e-service quality, penggunaan dimensi efisiensi didefinisikan kemudahan dan kecepatan mengakses dan menggunakan situs (Parasuraman et al., 2005)

Santos (2003) menemukan jika situs website menawarkan beberapa diskon, hadiah menarik atau insentif lainnya, konsumen akan cendrung membeli produk secara online dari pada pergi berbelanja ke jasa atau toko offline. Dengan demikian insentif dapat dibuktikan sebagai dimensi untuk mempertahankan atau membuat loyal pelanggan online, oleh karena itu (Peter and Olson, 2003) menyarankan bahwa perusahaan menempatkan lebih penekanan pada dimensi Insentif didalam membangun kualitas layanan online.

Berdasarkan uraian di atas, penelitian ini bertujuan untuk menganalisis pengaruh penerapan e-service quality dalam menciptakan e-loyalty dengan melakukan studi pada pengguna layanan jasa travel online Traveloka di Indonesia.

\section{Metode}

Jenis penelitian ini berbentuk studi Deskriptif Kausal melalui pengujian hipotesis. Sekaran (Sekaran, 2003) menyatakan Studi deskriptif (descriptive study) bertujuan untuk mengambarkan karakteristik, aspek-aspek dari fenomena interest yang relevan dari orang, kejadian atau situasi dalam bentuk pengumpulan data kualitatif. Studi deskriptif akan membantu peneliti didalam memahami karakteristik keleompok dalam situasi tertentu.

Lokasi penelitian tersebar secara geografis mengambil lokasi pengguna layanan jasa Traveloka di wilayah Indonesia, di mana respondennya pengguna aktif layanan jasa travel online dan penyebaran kuesioner akan dilakukan melalui grup atau komunitas di media sosial melalui jajak pendapat/ survey online dengan menggunakan Platform digital survey yang dilinkkan dengan platfom aplikasi/website online travel agencies di Indonesia dan juga untuk memperkuat pengujian desain survey digunakan Google Doc yang dilinkkan dengan WhatsApp.

\section{Jenis dan Sumber Data}

Jenis data yang digunakan dalam penelitian ini adalah data kualitatif yang disajikan dalam bentuk tulisan dan gambar yang memiliki makna.

Sumber data terdiri dari: data primer yang berasal dari hasil kuesioner yang disebarkan pada responden dan data sekunder berupa data-data yang diperoleh dari buku, jurnal, laporan yang berkaitan dengan penelitan ini

\section{Populasi dan Sampel}

Populasi dalam penelitian ini adalah seluruh pengguna aktif Traveloka di Indonesia yang tersebar secara geografis, sehingga besarnya populasi tidak diketahui dengan pasti, untuk menghitung jumlah sampel minimum berdasarkan pertimbangan parameter yang diamati dan memperkuat signifikansi hasil pengukuran digunakan jumlah sampel minimal 200, dengan target sampel sebesar 262 responden pengguna jasa layanan Traveloka di Indonesia.

Teknik penarikan sampel yang digunakan dalam penelitian ini adalah Non-Probability Sampling dengan teknik Purposive Sampling, dengan kriteria yang menjadi sampel atau responden sebagai berikut:

1. Pengguna aktif Traveloka di Indonesia Minimal 6 bulan terakhir.

2. Pengguna layanan Traveloka bersedia mengisi kuesioner Secara online.

3. Berumur lebih dari 17 tahun.

\section{Definisi Operasional Variabel}

Variabel yang digunakan dalam penelitian ini didefinisikan sebagai berikut:

Kualitas layanan online adalah suatu kondisi yang menggambarkan persepsi pengguna jasa terhadap kinerja Iayanan yang diberikan oleh penyedia jasa layanan online dalam hal ini difokuskan pada layanan jasa perjalanan online.

Website design menurut Blut (2016) dan Zeithaml et. al., (2013) merupakan dimensi pertama dari kualitas layanan jasa elektronik. Dalam fase ini sebagai indicator ukuran penilaian yaitu pelanggan tertarik pada kualitas informasi yang diberikan, estetika situs website ketika membentuk keputusan 
pembelian, kelancaran proses pembelian, kenyamanan menjelajahi situs website, pemilihan produk layanan situs elektronik, ktersedian pilihan layanan, informasi tentang harga layanan yang diinginkan, personalisasi informasi dan ketersedian situs website secara permanen.

Fulfillment atau pemenuhan menurut Blut (2016), Zeithaml et. al., (2013) menyatakan hal ini merupakan salah satu dimensi dari kualitas pelayanan elektronik yang meliputi aktual kinerja perusahaan kontras dengan apa yang dijanjikan melalui website, mencakup akurasi janji layanan, seperti ketersediaan stok produk dan pengiriman produk sesuai dengan waktu yang dijanjikan. Blut (2016) adalah dimensi yang mencakup pemenuhan pesanan yang mengacu pada kemampuan layanan jasa online untuk memastikan bahwa pelanggan menerima apa yang mereka inginkan terpenuhi.

Customer Service atau layanan pelanggan, Blut (2016) menyatakan bahwa layanan pelanggan berkaitan dengan dukungan pelanggan online-sebelum, selama dan setelah pesanan jasa online dirasakan.

Security/Privacy atau keamanan/privasi. Blut (2016), menyatakan bahwa Security/privacy merupakan salah satu dimensi dari kualitas pelayanan elektronik yang meliputi jaminan dan kemampuan perusahaan dalam menjaga integritas data dari pelanggan. Blut (2016) menyatakan bahwa keamanan/privasi merujuk pada kehawatiran pelanggan tentang kemungkinan penyimpangan atau resiko keamanan/ privasi. Pelanggan sering menghindari layanan online ketika mereka merasa bahwa jenis pembayaran yang ditawarkan secara online tidak aman dan informasi personal pelanggan selama atau setelah transaksi tidaka bersifat pribadi. Pengguna hawatir bahwa informasi pribadi (privasi) seperti kontak pribadi dapat digunakan oleh pihak lain untuk kepentingan promosi dan hal lainnya.

Efficiency atau Efisiensi dalam penulisan disertasi ini sebagai tawaran dimensi pengenbangan dari rekonstruksi model dimensi e-servqual temuan Blut (2016), di mana menurut Sahadev dan Purani (2008), Pool et. al., (2016) Efisiensi didefinisikan sebagai kemudahan dan kecepatan mengakses dan menggunakan situs. Suatu provider atau perusahaan online yang efisien adalah suatu layanan online barang atau jasa yang pemenuhannya dengan cepat, lancar dan dengan biaya yang minimum. Dalam e-service quality, penggunaan efisiensi adalah kemudahan dan kecepatan mengakses dan menggunakan situs (Zeithaml, et. al., 2013:91). Pada penelitian ini indikator yang digunakan mengacu pada penelitian empiris dikemukakan oleh Sahadev dan Purani, (2008).

Menurut Santos (2003) insentif didefinisikan sebagai dorongan yang diberikan oleh penyedia website kepada pelanggan untuk mencari dan menggunakan situs website, termasuk imbalan untuk melakukan transaksi. Karena situs website adalah lingkungan yang sangat kompetitif, tawaran insentif mendorong pengguna layanan online untuk menilai situs website, dan tertarik untuk terlibat dalam pembelian/transaksi online, bahkan konsumen tertarik untuk berpartisipasi dalam riset pasar. Hal ini juga meningkatkan retensi dan komunikasi kata dari mulut terhadap upaya menciptakan loyalitas konsumen online. Adapun indikator untuk mengukur efektifitas dimensi Insentif melalui Tawaran program diskon situs website, penawaran hadiah-hadiah, program poin belanja dan program insentif lainnya (Santos, 2003).

E-loyalty atau kesetiaan pelanggan/penguna jasa layanan online adalah suatu kondisi dimana pengguna layanan merasa senang mempunyai hubungan dengan layanan travel online, yang dicirikan dengan adanya transaksi berulang kali dan berperilaku sebagai pengguna layanan serta menunjukkan kekebalan terhadap penawaran layanan travel online yang sejenis. Kassim dan Abdullah, (2010) mendefinisikan indikator pengukuran loyalitas pelanggan online terdiri dari dua dimensi utama yaitu WOM atau Word of Mouth dan Intention to repurchase.

\section{Metode Analisis Data}

Analisis data dalam penelitian ini menggunakan analisis regresi linier berganda.

\section{Hasil dan Pembahasan}

\section{Profil responden}

Gambaran karakteristik individu dari 262 responden, dideskripsikan dengan jenis kelamin, umur, dan pekerjaan. Dimana sebagian besar pengguna jasa online travel agen yang berjenis kelamin laki-laki berjumlah 141 orang (54\%) dan perempuan dengan jumlah 121 orang (46\%). Lebih dari $46 \%$ atau 120 responden mempunyai umur berkisar 36-50 tahun, hal ini mengindikasikan bahwa usia ini menuntut penghematan waktu didalam pencaharian informasi perjalanan murah, aman, efektif dan efisien sehingga mengharuskan mereka menggunakan jasa online travel Agen (OTA) tanpa meninggalkan pekerjaan rutin atau tempat kerja. Sekitar 36,64\% atau 96 responden bekerja sebagai pegawai swasta hal ini dikarenakan pegawai swasta pada umumnya sering memanfaatkan waktu liburan ataupun kegiatan lainnya melalui online travel agen (OTA).

Hasil penelitian dirangkum dalam tabel hasil uji regresi linier berganda berikut ini:

Tabel 2. Hasil Uji Regresi Linier Berganda

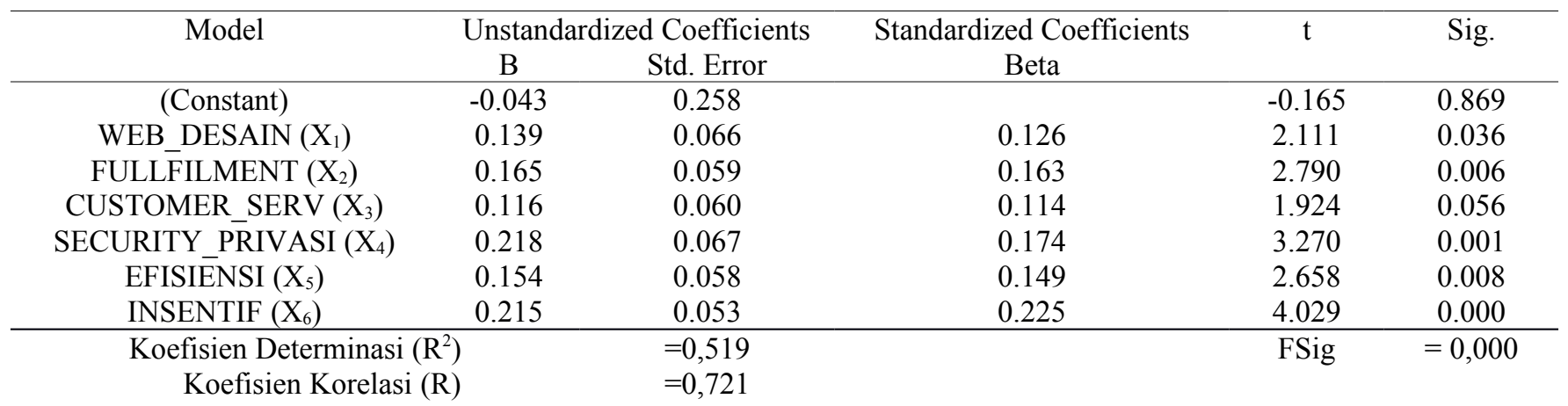


Berdasarkan hasil Tabel 2 hasil uji regresi linear berganda diatas, nilai sig. F yaitu 0,000 , mengandung arti bahwa nilai tersebut lebih kecil dibandingkan dengan nilai yang ditetapkan yaitu $\alpha=0,05$ dengan tingkat kepercayaan $95 \%$. Hal ini berarti bahwa variabel e-service quality secara serempak berpengaruh signifikan terhadap e-loyalitas pada pengguna aplikasi Traveloka.

Selanjutnya, secara parsial variabel Fullfilment (X2), Security privasi (X4), efisiensi (X5) dan insentif (X6) berpengaruh signifikan terhadap e-loyalitas pada pengguna aplikasi Traveloka. Terlihat ditabel bahwa keempat variable ini memiliki nilai signifikan $\mathrm{t}$ kurang dari nilai yang ditetapkan yaitu $\alpha=0,05$. Namun untuk Variabel Web desain custumer service berpengaruh tidak signifikan terhadap eloyality karena memiliki nilai signifikan $\mathrm{t}$ lebih dari nilai yang ditetapkan yaitu $\alpha=0,05$.

Dari hasil penelitian diperoleh nilai Koefisien korelasi (R) sebesar 0,721 ini berarti bahwa korelasi antar variabel independen (e-service quality) dengan variabel dependen (eloyality) memiliki korelasi keeratan kuat sebesar 0,721. Koefisien determinasi $\left(\mathrm{R}^{2}\right)$ dipakai sebagai alat menganalisis untuk membuktikan besarnya andil variabel independen (eservice quality) pada variabel dependen yaitu e-loyality. Hasil pengujian memperlihatkan nilai koefisien determinasi $\left(\mathrm{R}^{2}\right)$ sebesar 0,519 yang artinya adalah andil dari variabel eservice quality yang digunakan dalam peneitian ini, terhadap e-loyality adalah sebesar $51 \%$ sedangkan sisanya $49 \%$ dipengaruhi oleh variabel lain diluar model yang digunakan dalam penelitian ini.

Kualitas layanan merupakan ukuran atas kesuksesan perusahaan, dalam hal ini Traveloka. Pelanggan yang sudah mendapatkan layanan yang berkualitas dari pihak Traveloka, pastinya menimbulkan perasaan puas yang disebut dengan kepuasan pelanggan. Pelanggan yang puas selalu memberikan penilaian secara obyektif, sehingga yang pada akhirnya meningkatkan loyalitas pelanggan. Loyalitas pelanggan diperlukan oleh perusahaan karena memberikan dampak yang baik bagi perusahaan, contohnya: pelanggan yang loyal akan melakukan pembelian kembali dan merekomendasikan pada teman, sahabat dan kerabatnya. Tanpa loyalitas dari pelanggan, perusahaan susah untuk berkembang. Harapan pelanggan adalah mendapatkan pelayanan dengan cepat, sesuai dengan keinginannya. Misalnya: pelayanan sesuai dengan jangkauan pembiayaan yang dikenakan.

Hasil penelitian ini sesuai dengan penelitian yang dilakukan oleh Ting et, al (2016) yang mengungkapkan bahwa e-service quality berpengaruh positif terhadap loyalitas pelanggan. Dengan kata lain, jika pelanggan mendapatkan pengalaman bertransaksi yang baik dan cepat, maka tingkat e-loyality pada aplikasi Traveloka akan meningkat.

\section{Simpulan}

Berdasarkan karakteristik responden, ditemukan segmen pengguna online travel Agent (OTA) yang mewakili populasi, sebagai berikut: berjenis kelamin laki-laki, berusia antara 36-50 tahun, pekerjaan pegawai swasta, berpendapatan $5-10$ juta per bulan, layanan yang sering digunakan adalah pencarian maskapai/penerbangan, menggunakan aplikasi sejak 1 sampai 1, 6 tahun. Berdasarkan hasil penelitian, pada indikator kualitas informasi, yaitu sub indikator: Situs Web memenuhi kebutuhan informasi terbukti memiliki nilai mean tertinggi. Indikator customer service, pada sub indicator: menyediakan pilihan yang mudah untuk pengembalian transaksi dan penanganan pengembalian produk/layanan dengan baik, memiliki nilai mean terendah.

\section{Saran}

Diharapkan hasil penelitian ini memberikan kontribusi positif bagi pihak manajemen traveloka agar selalu meningkatkan eservice qualitynya, terutama pada menu penanganan pengembalian/refund produk yang mereka jual, agar tidak merugikan pelaggan. Selain itu, manajemen Traveloka hendaknya memberikan perhatian lebih terhadap segmen yang ditemukan dalam penelitian ini, sehingga dapat membuat strategi pemasaran yang tepat agar tidak salah sasaran. Situs web Traveloka sebaiknya selalu di update sesuai dengan kebutuhan konsumen, dan hal ini dapat dijadikan sebagai salah satu dasar untuk pengambilan keputusan bagi pihak manajemen Traveloka.

\section{Referensi}

Anderson, R. E., \& Srinivasan, S. S. (2003). E-Satisfaction and E-Loyalty: A Contingency Framework. Psychology and Marketing, 20(2), 123-138. https://doi.org/10.1002/mar.10063

Bakri, N., Ibrahim, R., Salleh, T. S. A. @, Zin, Z. M., Egmont-Petersen, M., de Ridder, D., ... Wang, X. (2015). A comparison of waveform processing algorithms for single-wavelength LiDAR bathymetry. In Journal of Visual Communication and Image Representation (Vol. 126). https://doi.org/10.1109/JBHI.2014.2352119

Blut, M. (2016). E-Service Quality: Development of a Hierarchical Model. Journal of Retailing, 92(4), 500-517. https://doi.org/10.1016/j.jretai.2016.09.002

Chang, H. H., \& Chen, S. W. (2008). The impact of online store environment cues on purchase intention: Trust and perceived risk as a mediator. Online Information Review, 32(6), 818-841. https://doi.org/10.1108/14684520810923953

Choo, H., Park, S.-Y., \& Petrick, J. F. (2011). The Influence of the Resident's Identification with a Tourism Destination Brand on Their Behavior. Journal of Hospitality Marketing \& Management, 20(2), 198-216. https://doi.org/10.1080/19368623.2011.536079

Chu, P. Y., Lee, G. Y., \& Chao, Y. (2012). Service quality, customer satisfaction, customer trust, and loyalty in an e-banking context. Social Behavior and Personality, 40(8), 1271-1284. https://doi.org/10.2224/sbp.2012.40.8.1271

Gaertner, N., \& Smith, M. (2001). E-commerce in a Web-based environment: Auditing relative advantages in the Australian health sector. Managerial Auditing Journal, 16(6), 347-365. https://doi.org/10.1108/02686900110395497

Gefen, D. (2002). Customer Loyalty in e-Commerce Settings.pdf.crdownload. Journal of the Association for Information Systems, 3(1), 27-51. Retrieved from https://pdfs.semanticscholar.org/00f2/f77fe6480f66c2982010a091e8c $76 \mathrm{c} 61 \mathrm{~b} 7 \mathrm{ff} . \mathrm{pdf}$

Islam, M. A., Khadem, M., \& Sayem, A. (2012). Service quality, customer satisfaction and customer loyalty analysis in Bangladesh apparel fashion retail: An empirical study. International Journal of Fashion Design, Technology and Education, 5(3), 213-224. https://doi.org/10.1080/17543266.2012.723754

Jonathan, H. (2013). Analisis Pengaruh E-Service Quality terhadap Customer Satisfaction yang Berdampak pada Customer Loyalty PT Bayu Buana Travel Tbk. The Winners, 14(2), 104. https://doi.org/10.21512/tw.v14i2.650

Kassim, N., \& Asiah Abdullah, nor. (2010). The effect of perceived service quality dimensions on customer satisfaction, trust, and loyalty in ecommerce settings: A cross cultural analysis. Asia Pacific Journal of Marketing and Logistics, 22(3), 351-371. https://doi.org/10.1108/13555851011062269

Kim, J., Jin, B., \& Swinney, J. L. (2009). The role of etail quality, esatisfaction and e-trust in online loyalty development process. Journal of Retailing and Consumer Services, 16(4), 239-247. 
https://doi.org/10.1016/j.jretconser.2008.11.019

Kotler, P., \& Keller, K. L. (2016). Marketing Management. In Global Edition (Vol. 15E). https://doi.org/10.1080/08911760903022556

Lai, W.-H., \& Vinh, N. Q. (2013). Online promotion and its influence on destination awareness and loyalty in the tourism industry. Advances in Management and Applied Economics, 3(3), 15-30.

Laudon, K. C., \& Traver, C. G. (2017). E - commerce.

Li, H., Liu, Y., \& Suomi, R. (2009). Measurement of eservice quality: An empirical study on online travel service. 17th European Conference on Information Systems, ECIS 2009.

Parasuraman, A., Zeithaml, V. A., \& Malhotra, A. (2005). E-S-QUAL a multiple-item scale for assessing electronic service quality. Journal of Service Research, 7(3), 213-233. https://doi.org/10.1177/1094670504271156

Peter and Olson, J. (2003). E-service quality: A model of virtual service quality dimensions. Managing Service Quality: An International Journal, 13(3), 233-246. https://doi.org/10.1108/09604520310476490

Pool, J. K., Dehghan, A., Jamkhaneh, H. B., Jaberi, A., \& Sharifkhani, M. (2018). The effect of e-service quality on football fan satisfaction and fan loyalty toward the websites of their favorable football teams. Sports Media, Marketing, and Management: Breakthroughs in Research and Practice, 12(1), 470-485. https://doi.org/10.4018/9781-5225-5475-2.ch024

Ribbink, D., Streukens, S., Van Riel, A. C. R., \& Liljander, V. (2004). Comfort your online customer: Quality, trust and loyalty on the internet. Managing Service Quality: An International Journal, 14(6), 446-456. https://doi.org/10.1108/09604520410569784

Rowley, J. (2006). An analysis of the e-service literature: Towards a research agenda. Internet Research, 16(3), 339-359. https://doi.org/10.1108/10662240610673736

Sahadev, S., \& Purani, K. (2008). Modelling the consequences of e-service quality. Marketing Intelligence and Planning, 26(6), 605-620. https://doi.org/10.1108/02634500810902857

Sekaran, U. (2003). Research Methods for Business (Vol. 65). https://doi.org/10.1017/CBO9781107415324.004

Sukma. (2019). 済無 No Title No Title. Journal of Chemical Information and Modeling, 53(9), 1689-1699. https://doi.org/10.1017/CBO9781107415324.004

Ting, O. S., Ariff, M. S. M., Zakuan, N., Sulaiman, Z., \& Saman, M. Z. M. (2016, May). E-service quality, e-satisfaction and e-loyalty of online shoppers in business to consumer market; Evidence form Malaysia In IOP Conference Series: Materials Science and Engineering (Vol 131, No. 1, p. 012012). IOP Publishing.

Tsang, N. K. F., Lai, M. T. H., \& Law, R. (2010). Measuring E-service quality for online travel agencies. Journal of Travel and Tourism Marketing, 27(3), 306-323. https://doi.org/10.1080/10548401003744743

Wolfinbarger, M., \& Gilly, M. C. (2003). eTailQ: Dimensionalizing, measuring and predicting etail quality. Journal of Retailing, 79(3), 183-198. https://doi.org/10.1016/S0022-4359(03)00034-4. 